\title{
A NEW SPECIES OF THE RARE GENUS AUSTRoterobia GIRAULT (HYMENOPTERA: PTEROMALIDAE: AUSTROTEROBIINAE) FROM WEST BENGAL, INDIA
}

\author{
T.C. Narendran ${ }^{1}$ and Bijankumar Das ${ }^{2}$ \\ ${ }^{1}$ Professor, Systematic Entomology Laboratory, Department of Zoology, University of Calicut, Kerala 673635, India. \\ E-mail: narendra@unical.ac.in \\ ${ }^{2}$ Senior Lecturer, Regional Research Station, Bidhan Chandra Krishi Viswavidyalaya, Mathurapur, P.O., West Bengal 732203, India.
}

\begin{abstract}
A new species of Pteromalidae, Austroterobia maldica sp. nov. parasitising an indetermined species of Icerya (Coccoidea) associated with Mango tree in West Bengal, India is described and its affinities are discussed.
\end{abstract}

\section{Keywords}

Hymenoptera, Pteromalidae, Austroterobia, new species, West Bengal

\begin{abstract}
Abbreviations
DZCU $=$ Department of Zoology, University of Calicut $\quad$ Fl to F5 = Funicular segments first to fifth MV = Marginal vein PMV $=$ Postmarginal vein

SMV $=$ Submarginal vein $\mathrm{OOL}=$ Ocellocular distance $\mathrm{POL}=$ Postocellar distance STV = Stigmal vein
\end{abstract}

\section{Introduction}

Girault (1938) described the genus Austroterobia with the type species Austroterobia partibrunnea Girault from Queensland, Australia. Later Boucek et al. (1979) and, Farooqi and Subba Rao (1986) reported an undetermined species from Delhi. Boucek (1988) reported that four undescribed species of Austroterobia are present in South Asia. The same author stated that (Boucek, 1988) Noyes and Boucek collected the type species from Queensland and New South Wales (Australia) during the period from 1976 to 1980. In the present paper a new species of this remarkable genus is described. Boucek (1988), stated that members of this genus are probably parasites of Margarodidae (Coccoidea). The new species described here is found parasitising an undetermined Icerya sp.associated with Mango tree in Malda, West Bengal.

Received 9 May 2000
Accepted 15 July 2000

\section{Austroterobia maldica sp. nov.}

(Figs. $1 \& 2$ )

\section{Material examined:}

Holotype: Female. 1.vi.1999. Coll. B.K. Das. Malda, West Bengal, India. DZCU, Calicut.

Paratypes: Six females and six males. 1.vi.1999. Coll. B.K. Das. Malda, West Bengal, India. DZCU, Calicut.

Host: Undetermined Icerya sp. (Margarodidae) on Mango tree.

Etymology: The species name is after its locality Malda of West Bengal.

\section{Diagnostic features:}

Holotype female: Length $1.39 \mathrm{~mm}$. Black with slight metallic green refringence on head and posterior half of gaster; antenna pale brown with scape pale yellow; eye brownish grey; ocelli pale reflecting yellow with a brownish patch on a side; mandibles pale brownish yellow; maxillary and labial palps pale yellow; pro, meso and meta pleura and propodeum dark brown; remaining 


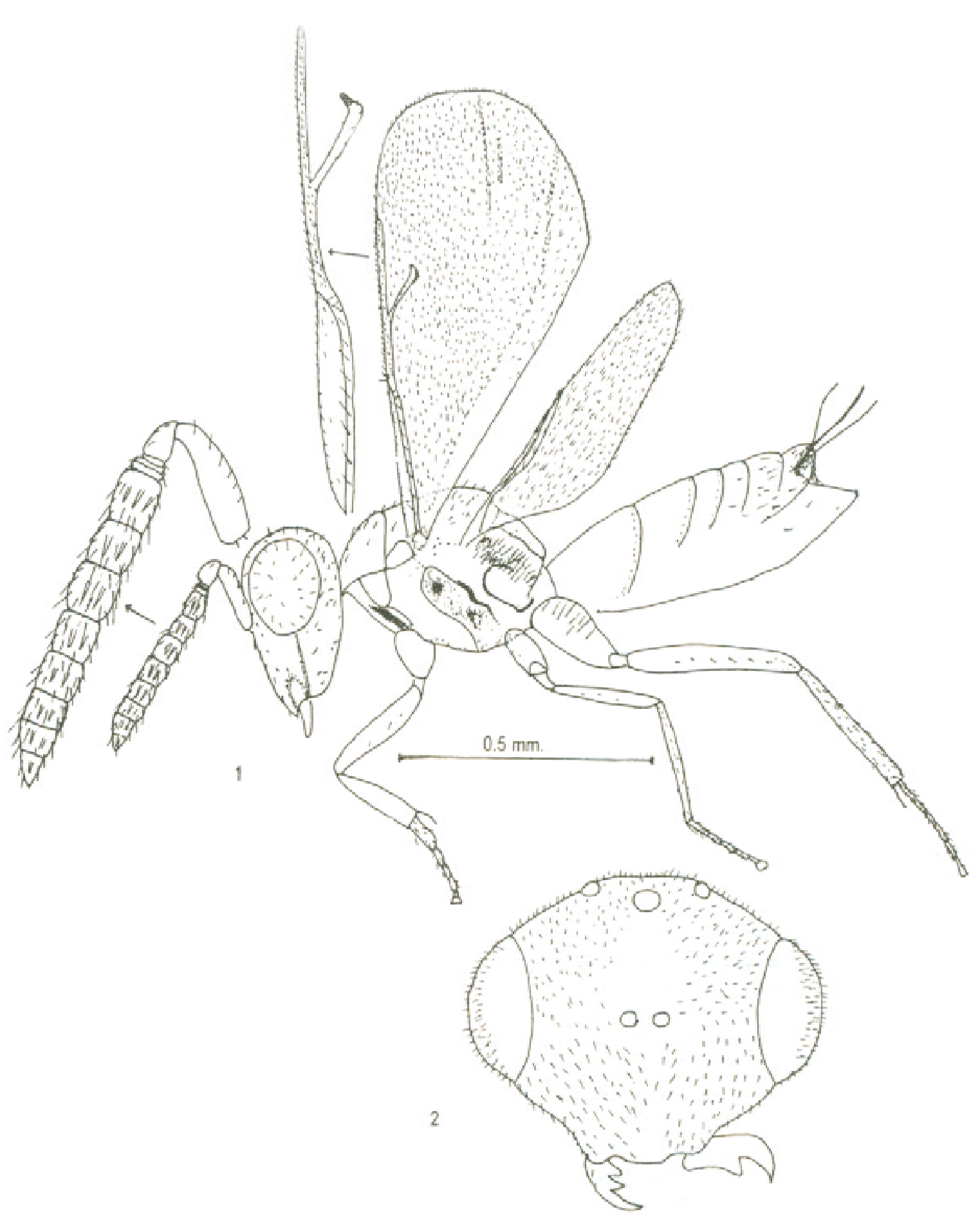

Figures 1-2. Austroterobia maldica sp. nov. female.

1. Body in profile; 2. Head in dorsal view. 
part of notum of mesosoma black; legs including all coxae pale yellow, except dark pretarsi; tegula pale brown; wings hyaline with veins and pubescence pale brown; gaster brownish black with basal tergite pale yellow, brownish black part with metallic green refringence. Pubescence on body dirty white and dense.

Head: Width in dorsal view 3x its median dorsal length; width in front view $1.38 \mathrm{x}$ distance between front ocellus and lower clypeal margin; frons and vertex reticulate with dense pubescence; clypeus not distinctly separate by a sulcus or line from face, lower margin entire and medially produced slightly (Fig.2); mandibles strong, sinuate with large teeth; left mandible with two teeth and right mandible with three sharp teeth, outer one very long. POL 1.3x OOL; gena reticulate; eye pubescent; maximum diameter of eye 1.12x length of malar sulcus in profile; malar sulcus vaguely indicated (could be detected only in certain lighting reflections). Scrobe shallow, hardly demarcated from frons. Antennal formula 11353; toruli near middle of frons (Fig.2); scape not reaching front ocellus. Relative length: width of antennal segments: scape $=32: 10$; pedicel $=10: 7 ; \mathrm{Fl}=13: 11$; $\mathrm{F} 2=12: 11 ; \mathrm{F} 3=12: 11 ; \mathrm{F} 4=11: 11 ; \mathrm{F} 5=10: 10 ;$ clava $=23: 9$.

Mesosoma: Pronotum not visible dorsally, strongly reduced; lateral panel with a deep oblique sulcus; mesosoma narrower than head in dorsal view (14:19); mesoscutum strongly transverse; rugosoreticulate; notauli deep only on anterior onethird, becoming faint towards posterior side (distinct only in certain lights) hardly complete. Scutellum undivided, converse, axillar sulcus smoothly continuous with transscutel suture; frenum distinct; propodeum with distinct median carina, plicae not converging but joining straightly the adpetiolar carina; submedian areas large and mostly smooth with faint reticulations; spiracles at metanotal margin, far beyond plicae. Metapleuron bare, large but not reaching hind wing base; mesopleuron depressed and with two deeper pit like depressions; prepectus triangular depressed along all borders. Forewing length $2.07 \mathrm{x}$ its maximum width relative lengths of forewing veins: $\mathrm{SMV}=56$; $\mathrm{MV}=27 ; \mathrm{PMV}=38 ; \mathrm{STV}=23$.

Gaster: length 1.56x length of mesosoma, collapsing dorsally, hypopygium plough-shaped ending beyond or at apex of gaster (Fig. 1); ovipositor projecting, 0.6x, as long as hind tibia.
Male: Length 1.14 - $1.2 \mathrm{~mm}$. Similar to female except in having second and third antennal anelli slightly longer.

\section{Discussion}

This new species differs from the only described species Austroterobia partibrunnea Girault (Girault, 1938) in having:

1. notauli not deep on its two-thirds from posterior side, hardly distinct (in A. partibrunnea notauli deep and complete)

2. hypopygium ending at or slightly beyond apex of gaster (in $A$. partibrunnea hypopygium ending near to gaster apex)

3. ovipositor $0.6 x$ length of hind tibia (shorter than $0.6 x$ length of hind tibia in A. partibrunnea)

4. propodeal plicae straightly joining adpetiolar carina, weak (in A. partibrunnea plicae converging to join adpetiolar carina, strongly developed when compared to the new species)

5. STV a little longer than 1.17x MV (in partibrunnea STV almost equal to MV)

6. gaster 1.56x as long as mesosoma (in A. partibrunnea gaster $1.3 \mathrm{x}$ as long as mesosoma)

7. both female and male with Tl yellow (only in male $\mathrm{Tl}$ yellow in A. partibrunnea)

\section{Acknowledgements}

The senior author of this paper is grateful to the authorities of University of Calicut for providing facilities.

\section{References}

Boucek, Z. (1988). Australasian Chalcidoidea (Hymenoptera). C.A.B. International, Wallingford, U.K. 832 pp.

Boucek, Z., B.R. Subba Rao and S.I. Farooqi (1979). A preliminary review of Pteromalidae (Hymenoptera) of India and adjacent countries. Oriental Insects 12: 433 -467.

Farooqi, S.I. and B.R. Subba Rao (1986). Family Pteromalidae pp. 279-306. In: B.R. Subba Rao and M. Hayat, editors. The Chalcidoidea (Insecta: Hymenoptera) of India and adjacent countries. Oriental Insects 20: $1-430$.

Girault, A.A. (1938). Some new Australian insects which are parasites (Hym. Chalcidoidea). Revta. Ent. Rio de J. 8: 80-89. 